\title{
PENINGKATAN KUALITAS PRODUKSI GARAM MENGGUNAKAN TEKNOLOGI GEOMEMBRAN
}

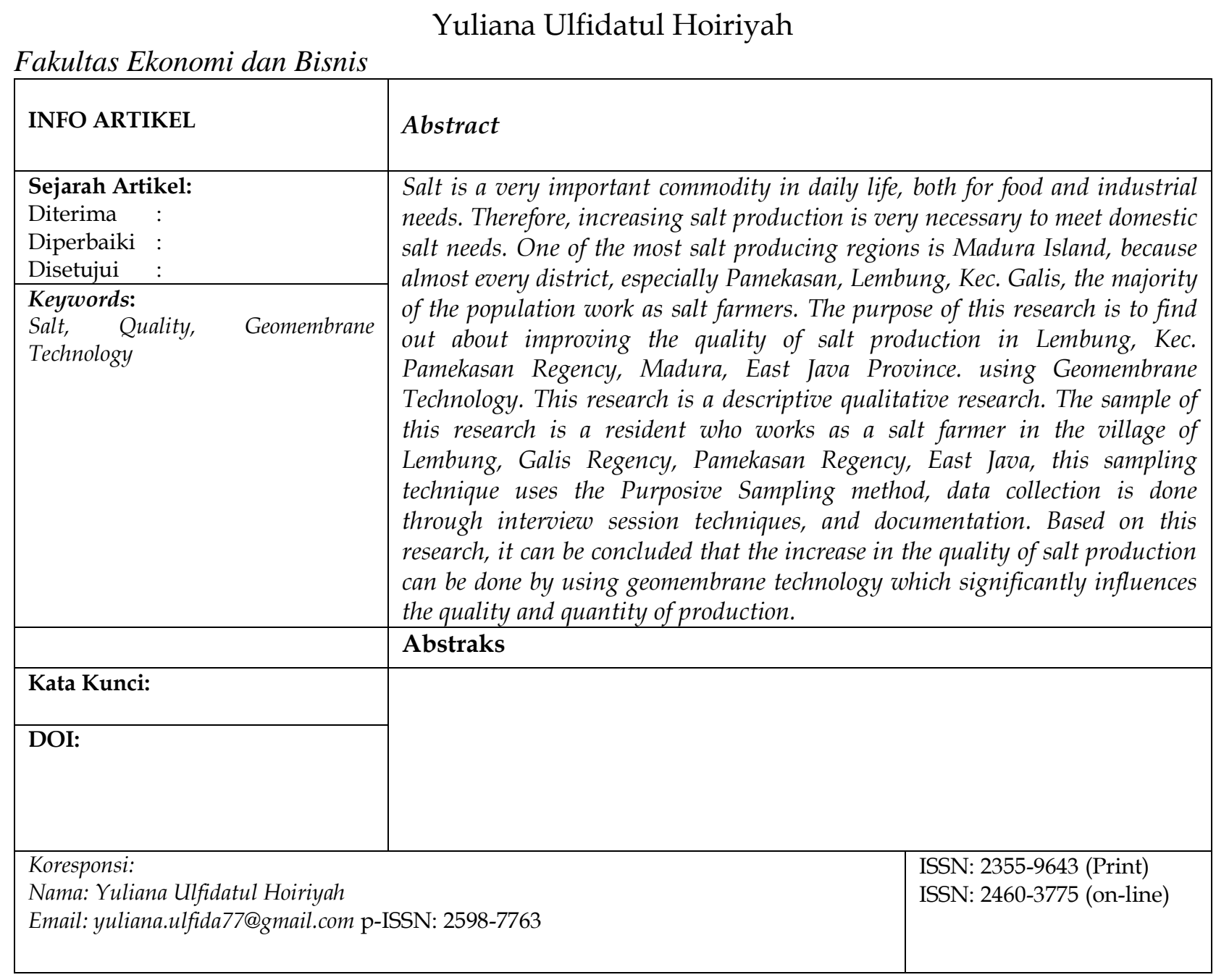

\section{PENDAHULUAN}

Garam merupakan komoditas yang sangat penting bagi kehidupan Masyarakat.Selain untuk dikonsumsi,garam banyak diperlukan dalam beberapa industri,diantaranya untuk pengawetan dan campuran bahan kimia.garam alami mengandung senyawa magnesium klorida, magnesium sulfat, magnesium bromida, dan senyawa runut lainnya. Menurut Sulistyaningsih ( Wiwin puspita hadi et al,2017). garam adalah senyawa Ionik yang terdiri dari ion positif (Kation) dan Ion negatif (anion), sehingga membentuk senyawa netral (tanpa bermuatan ). Garam terbentuk dari hasil reaksi asam dan basa. Komponen anion dan kation dapat berupa senyawa organik seperti klorida $\left(\mathrm{cl}^{-}\right)$, dan juga senyawa organik seperti asetat $\left(\mathrm{CH}_{3} \mathrm{COO}^{-}\right)$, serta ion monoatomik seperti fluorida $\left(\mathrm{F}^{-}\right)$, serta ion poliatomik seperti sulfat $\left(\mathrm{SO}^{2-}\right)$.

Kualitas garam bergantung pada kadar kandungan $\mathrm{NaCl}$ dalam garam.sedangkan kandungan $\mathrm{NaCl}$ dalam garam bergantung pada seberapa pekat air laut yang akan di proses menjadi garam dan lokasi dari mana air laut tersebut di ambil, selain faktor air laut yang akan di proses, tempat pengkristalan juga sangat 
berpengaruh terhadap kualitas garam yang akan di produksi. Petakan tanah atau bisa di sebut meja garam merupakan lahan yang digunakan oleh petani garam dalam proses pengkristalan air laut menjadi butira-butiran kristal yang di sebut garam. Tanah meja garam diupayakan mempunyai tekstur keras melalui proses kesap dan guluk garam memiliki permeabilitas yang rendah dan lahan tidak mudah rusak (Oktavian,2013). Menggunakan meja tanah menjadi salah satu faktor penyebab rendahnya kualitas dan kuantitas garam yang dihasilkan dikarenakan pada kristal-kristal garam pada saat panen akan bercampur dengan tanah yang menyebakan warna dari garam menjadi sedikit buram. Oleh karena itu, adanya penerapan teknologi baru sangat di butuhkan dalam proses pengkristalan garam agar kualitas dan hasil produksi meningkat. Pembuatan garam dengan menggunakan lahan atau meja garam yang berbeda akan menghasilkan kualitas dan hasil garam yang berbeda pula.

Dengan memproduksi garam menggunakan Teknologi Geomembran diharapkan dapat meningkatkan kualitas dan kuantitas hasil produksi, Geomembran sendiri yaitu adalah salah satu jenis material Geosintetik yang berfungsi sebagai lapis kedap air yang terbuat dari bahan sintetik semacam plastik. Sehingga dengan menggunakan Geomembran pengkristalan garam dapat dilakukan tanpa harus bersentuhan dengan tanah secara langsung. Geomembran ini dapat menyerap panas sinar matahari lebih cepat dibangdingkan dengan menggunakan meja garam yang terbuat dari tanah sehingga selain kualitas hasil produksi juga akan mengalami peningkatan. Dengan demikian, penulisan artikel ini bertujuan untuk menjelaskan peningkatan kualitas garam yang di produksi menggunakan Teknologi Geomembran.

Berdasarkan latar belakang
tersebut,Penelitian ini bertujuan untuk Menjelaskan Metode peningkatan Produksi garam menggunakan teknologi Geomembran di Desa Lembung, Kec.Galis, Kab.Pamekasan, Provinsi Jawa Timur dengan pendekatan melalui sesi tanya jawab kepada salah satu Warga yang berprofesi sebagai petani garam serta sudah menerapkan Teknologi Geomembran.

\section{KAJIAN TEORI \\ Pengertian Garam}

Garam merupakan salah satu kebutuhan yang merupakan pelengkap dari kebutuhan pangan dan merupakan sumber elektrolit bagi tubuh manusia. Secara fisik, garam adalah benda padatan berwarna putih berbentuk kristal yang merupakan kumpulan senyawa dengan bagian terbesar $\mathrm{NaCl}(>80 \%)$ serta senyawa lainnya seperti $\mathrm{CaSO} 4, \mathrm{MgSO} 4, \mathrm{MgCl}$, dan lain-lain (Marihati dan Muryati, 2008). Garam mempunyai sifat/karakteristik higroskopis yang berarti mudah menyerap air dan titik lebur pada tingkat suhu $801^{\circ} \mathrm{C}$ (www.wikipedia.org).

Natrium klorida membentuk kristal pada keadaan kering, tetapi seperti garam lainnya dalam tubuh, mudah dilarutkan dalam air. Jika garam larut dalam air, komponennya terpisah sebagai partikel yang disebut ion. Partikel ion terlarut ini dikenal sebagai elektrolit. Kadar (konsentrasi) setiap elektrolit dalam larutan dari garam terlarut dapat diukur dan biasanya dihitung dalam satuan miliekuivalen dalam setiap volume larutan (mEq/L).

Berikut ini merupakan karakteristik natrium klorida $(\mathrm{NaCl})$ :

Nama IUPAC

: Natrium klorida

Nama lain

: Garam dapur, halit

Molecular formula $: \mathrm{NaCl}$

Massa molar

: $58,443 \mathrm{~g} / \mathrm{mol}$

Penampilan

: Tak berwarna/putih

Kepadatan

kristal padat

Titik lebur

: $2,165 \mathrm{~g} / \mathrm{cm} 3$

: $801{ }^{\circ} \mathrm{C}, 1074 \mathrm{~K}$,

$1474{ }^{\circ} \mathrm{F}$

$\begin{aligned} \text { Kelarutan dalam air } & : 356 \mathrm{~g} / \mathrm{L}\left(0{ }^{\circ} \mathrm{C}\right) \\ & 359 \mathrm{~g} / \mathrm{L}\left(25^{\circ} \mathrm{C}\right) \\ & 391 \mathrm{~g} / \mathrm{L}\left(100^{\circ} \mathrm{C}\right)\end{aligned}$

Natrium (Na) adalah salah satu unsur alkali utama dan merupakan kation yang penting di perairan. Hampir semua senyawa natrium mudah larut dalam air dan bersifat sangat rektif. Hampir semua perairan alami mengandung natrium, dengan kadar bervariasi antara $1 \mathrm{mg} /$ liter hingga ribuan $\mathrm{mg}$ /liter. Kadar natrium pada perairan laut dapat mencapai $10.500 \mathrm{mg} /$ liter atau lebih. Satu liter air laut mengandung sekitar $30 \mathrm{gr} \mathrm{NaCl}$ yang terdiri atas \pm 11 gram natrium. Kadar natrium pada 
perairan tawar alami kurang dari $50 \mathrm{mg} /$ liter, sedangkan pada air tanah dalam dapat lebih dari $50 \mathrm{mg} /$ liter. Pada brine, kadar natrium berkisar antara 25.000-100.000 mg/liter (Hefni, E., 2003).

Secara umum garam rakyat dikelompokan dalam tiga jenis, yaitu:

1. K-1 yaitu kualitas terbaik yang memenuhi syarat untuk bahan industri maupun untuk konsumsi dengan komposisi sebagai berikut:

- $\mathrm{NaCl}: 97,46 \%$

- $\mathrm{CaCl} 2: 0,723 \%$

- $\mathrm{CaSO} 4: 0,409 \%$

- $\mathrm{MgSO} 4: 0,04 \%$

- $\mathrm{H} 2 \mathrm{O}: 0,63 \%$

- Impurities : 0,65\%

2. K-2 yaitu kulitas di bawah K-1, garam jenis ini harus dikurangi kadar berbagai zat agar memenuhi standar sebagai bahan baku industri. Kadar garam ini berkisar antara 90-94\%.

3. K-3 merupakan garam kualitas terendah sebagai produksi rakyat. Biasanya kadarnya antara $88-90 \%$, kadang-kadang bercampur tanah, sehingga warnanya agak kecoklatan.

Adapun faktor-faktor teknis yang mempengaruhi produksi garam rakyat adalah sebagai berikut:

a. Air laut

Mutu air laut (terutama dari segi kadar garamnya (termasuk kontaminasi dengan air sungai) sangat mempengaruhi waktu yang diperlukan untuk pemekatan (penguapan).

\section{b. Keadaan cuaca}

- Panjang kemarau berpengaruh langsung terhadap daya penguapan air laut.

- Curah hujan (intensitas) dan pola hujan distribusinya dalam setahun rata-rata merupakan indikator yang berkaitan erat dengan panjang kemarau yang kesemuanya mempengaruhi daya penguapan air laut.

- Kecepatan angin, kelembaban udara, dan suhu udara sangat mempengaruhi kecepatan penguapan air, dimana semakin besar penguapan maka semakin besar jumlah kristal garam yang mengendap.

\section{c. Tanah}

- Sifat porositas tanah mempengaruhi kecepatan perembesan (kebocoran) air laut ke dalam tanah di peminihan ataupun di meja.

- Bila kecepatan perembesan ini lebih besar daripada kecepatan penguapannya, apalagi bila terjadi hujan selama pembuatan garam, maka tidak akan dihasilkan garam.

- Jenis tanah mempengaruhi pula warna dan ketidakmurnian (impurity) yang terbawa oleh garam yang dihasilkan.

\section{d. Pengaruh air}

- Pengaturan aliran dan tebal air dari peminihan satu ke berikutnya dalam kaitannya dengan faktor-faktor arah kecepatan angin dan kelembaban udara merupakan gabungan penguapan air (koefisien perpindahan massa).

- Kadar/kepekatan air tua yang masuk ke meja kristalisasi akan mempengaruhi mutu hasil.

- Pada kristalisasi garam, konsentrasi air garam harus antara $25-29{ }^{\circ} \mathrm{Be}$. Bila konsentrasi air tua belum mencapai $25^{\circ} \mathrm{Be}$ maka gips (kalsium sulfat) akan banyak mengendap, bila konsentrasi air tua lebih dari $29^{\circ}$ Be Magnesium akan banyak mengendap.

Kualitas Produk

Menurut Kotler dan Armstrong (2004: 354) "kualitas produk merupakan kemampuan suatu produk dalam melaksanakan fungsi dan kinerjanya yang dapat memenuhi kebutuhan dan keinginan pelanggan". Kualitas produk menjadi hal penting yang harus dimiliki oleh sebuah produk, sehingga produsen dituntut untuk menghasilkan produk yang berkualitas agar dapat menarik perhatiaan konsumen dan memenangkan pasar.

Menurut Tjiptono (2008:25), kualitas mencerminkan semua dimensi penawaran produk yang menghasilkan manfaat (benefits) bagi pelanggan. Kualitas suatu produk baik berupa barang atau jasa ditentukan melalui dimensidimensinya.

Dimensi kualitas produk menurut Tjiptono (2008:25) adalah:

a. Performance (kinerja)

b. Durability (daya tahan)

c. Conformance to specifications (kesesuaian

dengan spesifikasi)

d. Features (fitur)

e. Reliability (reliabilitas)

f. Aesthetics (estetika)

g. Perceived quality (kesan kualitas)

h. Serviceability (kemampuan layanan)

Teknologi Geomembran

Geomembrane adalah material dari bahan HDPE (High Density Polyethylene) yang fungsi utamanya sebagai material pelapis. Material ini sangat tahan terhadap bahan kimia, asam tinggi dan limbah sehingga sangat sesuai untuk aplikasi pelindung air, tanah terhadap berbagai macam limbah. Geomembrane memungkinkan 
ditempatkan pada areal yang bergeometri berlekuk - lekuk, dan mampu mengikuti kontur tanah yang tidak rata, seperti perbukitan, dan kolam. Polyethelene Geomembrane tersedia dalam permukaan halus maupun bertekstur dan juga tersedia dalam berbagai ketebalan.

Geomembrane dapat dipergunakan diberbagai disiplin, yaitu lingkungan hidup, geotechnic, transportasi dan aplikasi khusus seperti antara lain

1. Sebagai wadah untuk air siap minum (portable water)

2. Sebagai wadah persediaan air

3. Sebagai wadah cairan buangan / limbah (sewage sludge)

4. Sebagai wadah cairan berbahaya atau yang mengandung radio aktif

5. Sebagai wadah penyimpanan air dibawah tanah

6. Sebagai wadah solar ponds

7. Digelar untuk industri pertanian

8. Digelar untuk lapangan golf

9. Untuk keperluan decorative maupun pembuatan pond

10. Digelar untuk pembuatan kanal air, limbah cair, dan sungai kecil

11. Untuk tambak udang, ikan dan industri kelautan

12. Untuk landfill biogas, pond limbah sawit dan sebagainya

Karena geomembrane dapat dipergunakan diberbagai tempat atau tanah yang beragam tekstur, akhir -akhir ini geomembrane juga dipergunakan sebagai media produksi garam rakyat.

Kelebihan Geomembrane

1. Tahan terhadap larutan kimia

2. Daya tahan terhadap elongasi/kemuluran akibat deformasi tanah dasar

3. Tahan terhadap retak / pecah dan anti UV

4. Index leleh yang relative tinggi

5. Dapat dikombinasikan dengan berbagai desain struktur

Kelemahan Geomembrane

Namun demikian, Geomembrane juga rentan terhadap kerusakan fisik akibat penetrasi benda tajam seperti batu atau kerikil, api dan kesalahan instalasi atau perawatan akibat alat berat (Stamper, Compactor, dll). Kerusakan ini dapat menimbulkan lubang atau sobek pada bagianbagian tertentu dimana lebih dari 75\% diakibatkan oleh tekanan material diatasnya. Hal ini dapat diatasi dengan pemberian lapisan pelindung yang sesuai dengan tebal, tambahan plat, dan lain-lain.

\section{METODOLOGI}

Penelitian ini menggunakan pendekatan Tinjauan Literarur ( Library Reserch ) yang digunakan secara deskriptif Kualitatif dan sesi wawancara yang di lakukan pada warga di masing-masing Dusun Desa Lembung Kec.Galis Kab.Pamekasan Provinsi Jawa Timur yaitu dusun Bangkal dan Dusun Bungkaleng. Karya tulis ini memaparkan tentang cara meningkatkan hasil produksi garam di Desa Lembung Kec.Galis Kabupaten Pamekasan Provinsi Jawa Timur menggunakan Teknologi Geomembran.

\section{HASIL PENELITIAN DAN PEMBAHASAN}

A.Proses Pengaplikasian Teknologi Geomembrane pada Meja Garam

Pada proses pemasangan teknologi geomembran pada lahan atau meja garam melalui beberapa tahapan sebagai berikut:

1.Lahan yang sudah di siapkan yang berbentuk persegi panjang dengan ukuran $60 \mathrm{~m} \times 13 \mathrm{~m}$ di ratakan terlebih dahulu permukaannya.

2.Setelah lahan diratakan permukaannya langkah selanjutnya yaitu mengeringkan permukaan dasar lahan tersebut.

3.langkah yang terakhir yaitu pemasangan teknologi geomembran dengan cara menghamparkan ke seluruh permukaan tanah yang sudah diratakan dan di keringkan dengan ukuran yang telah di tetapkan.

B. Proses Produksi menggunakan Teknologi Geomembrane

Proses produksi garam menggunakan teknologi geomembran adalah dimulai dari tempat penampungan air muda yang di ambil dari air laut kemudian setelah tempat air penampungan penuh disalurkan ke tempat peminihan satu, setelah satu hari ada di tempat peminihan satu, kemudian di salurkan kembali ke tempat peminihan 2, ditempat peminihan 2,3,dan 4 prosesnya sama seperti pada tempat peminihan satu yaitu di diamkan selama 1 hari pada masing-masing tempat peminihan. Manfaat dari peminihan ini adalah untuk mengatur tingkat kepekatan dan kadar air laut sebelum menuju meja kristalisasi. 


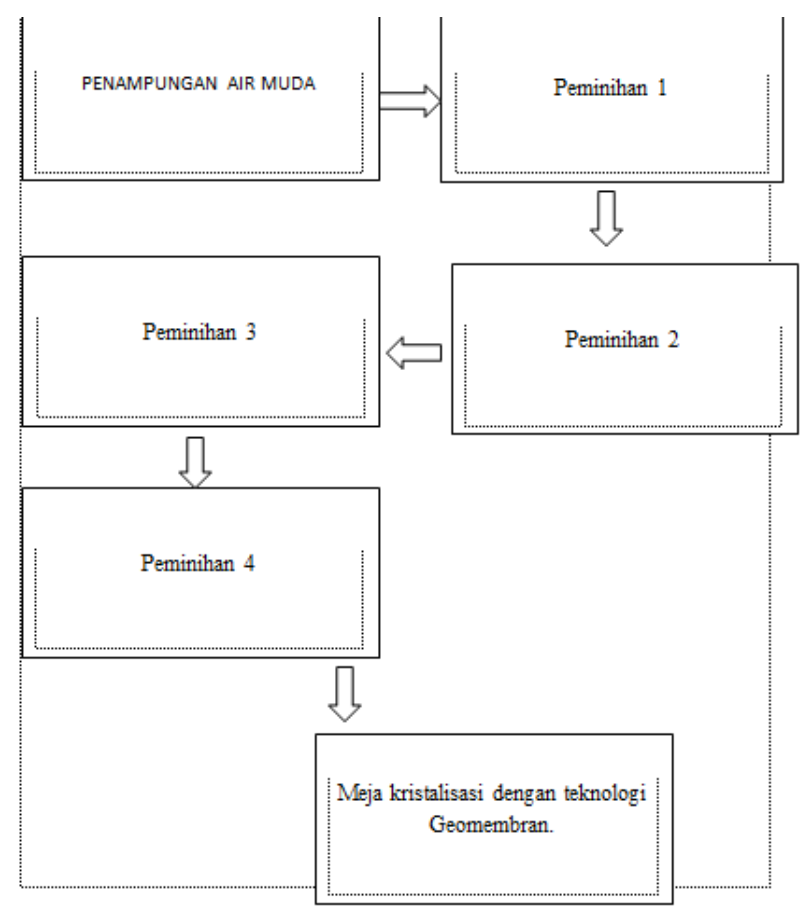

\section{C.Hasil Produksi garam menggunkan Teknologi Geomembran}

Untuk hasil hasil produksi garam yang menggunakan teknologi geomembran bergantung kepada berapa lama waktu yang di gunakan dalam pemgkristalan.rentan waktu pengkristalan minimum selama 7hari dan maksimal selama 15 hari. Untuk rentan waktu selama 7 hasil perkiraan hasil dalam $1 x$ panen sebanayak 5ton untuk satu lahan meja garam, dan untuk rentan waktu 15 hari yang diguanakan dalam proses pengkristalan dapat mengahasilkan sebanyak 13-15 ton dalam 1x panen. Namun, untuk penggunaan rentan waktu selama 15 hari ini bergantung kepada seberapa pekat kadar air dan persediaan air yang digunakan.

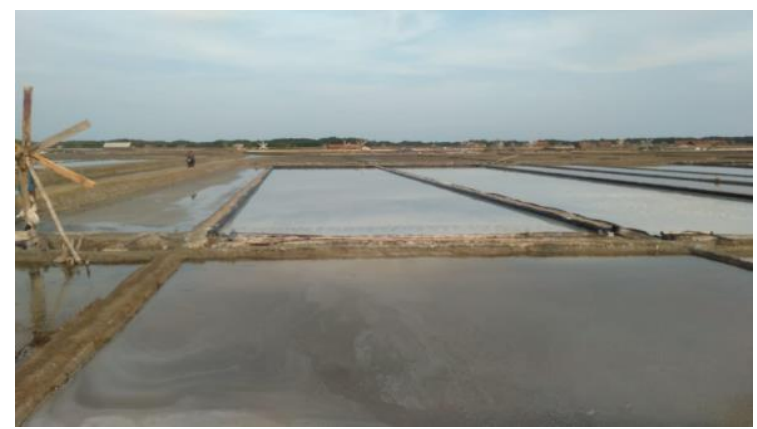

Gambar 2 : Gambar Lahan yang sudah di lapisi Teknologi Geomembran

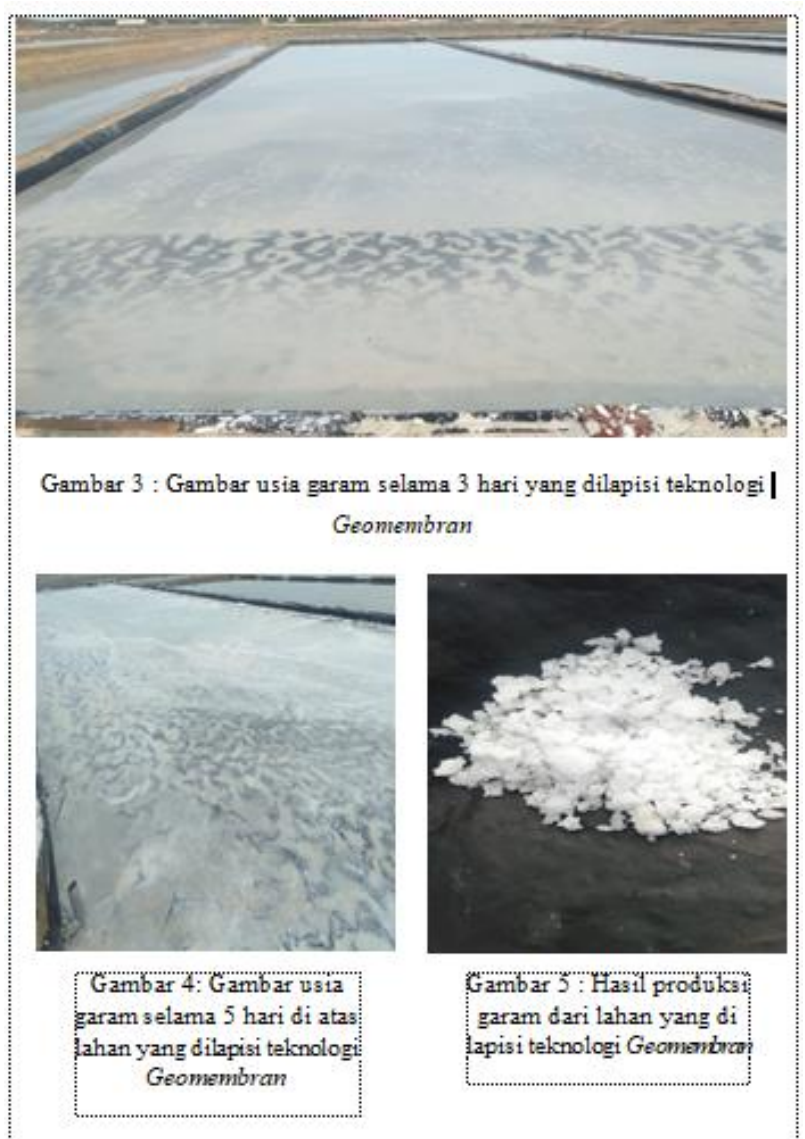

\section{Kelebihan Penggunaan Geomembran}

1.Kualitas garam yang di hasilkan lebih baik dibandingkan hasil produksi yang tidak menggunakan teknologi geomembran.kualitas disini berkaitan dengan ukuran kristal-kristal yang di hasilkan jauh lebih lebih besar dan bersih.

2.Tekonologi geomembran lebih cepat menyerap panas dibandingkan meja garam yang menggunakan tanah. Sehingga mempercepat peningkatan kepekatan kadar air.

3.Mempermudah proses panen. sekaligus lebih mudah membersihkan sisa-sisa zat kapur yang menempel di lapisan geomembran.

\section{Kelemahan Penggunaan Geomembran}

1.Penggunaan teknologi geomemran pada lapisan dasar permukaan meja garam mudah robek dikarenakan alat-alat yang digunakan proses panen garam.namun hal ini juga bergantung kepada ketebalan diameter geomembran yang di gunakan.

2.Jika garam yang sudah memasuki tahap pengkristalan di lahan yang menggunakan teknologi geomembran terkontaminasi air hujan akan melebur dan tidak bisa di gunakan kembali dalam proses produksi sehingga harus mengulang tahap produksi dari awal.

\section{Jumlah pengguna Geomembran}


Dari hasil penelitian yang di lakukan dapat diketahui bahwa jumlah petani garam yang menggunakan teknologi Geomembran lebih banyak dibandingkan dengan petani garam yang menggunakan meja kristalisasi menggunakan tanah. Serta jumlah petani garam di Dusun Bungkalen lebih banyak menggunakan Teknologi Geomembran dibandingkan dengan Dusun Bangkal dikarena luas lahan garam di dusun Bungkaleng lebih luas dibandingkan dusun Bangkal.

\begin{tabular}{|c|c|c|}
\hline \multicolumn{3}{|c|}{ Tabel 4.1 } \\
\hline Wilayah (Dusun) & $\begin{array}{c}\text { Menggunakan } \\
\text { Geomembran }\end{array}$ & $\begin{array}{c}\text { Tanpa Menggunakan } \\
\text { Geomembran }\end{array}$ \\
\hline Dusun Bangkal & 40 Orang & 30 Orang \\
\hline Dusun Bungkaleng & 300 Orang & 150 Orang \\
\hline
\end{tabular}

Dengan demikian Peningkatan Kualitas Garam dengan menggunakan teknologi Geomembran di Desa Lembung Kec.Galis Kab.Pamekasan Prov.Jawa timur sudah terlaksana mengingat kelebihan pengguaan teknologi Geomembran yang dapat meningkatkan kualitas garam baik dari segi warna kristal garam yang lebih bersih maupun dari segi kandungan $\mathrm{NaCl}$ dalam garam yang lebih tinggi dibandingkan dengan Garam yang di produksi menggunakan meja kristalilasi dari tanah atau secara Tradisional.

\section{Analisis dan Pembahasan}

Dari hasil penelitian tersebut menunjukkan bahwa penggunaan teknologi geomembran pada lapisan meja garam di Desa Lembung, Kec.Galis, Kab.Pamekasan, Provinsi Jawa Timur secara berpengaruh terhadap peningkatan kualitas hasil produksi berupa kristal garam yang dihasilkan lebih bersih dan kuantitas dalam satu kali panen lebih banyak di bandingkan dengan hasil panen lahan yang tidak menggunakan teknologi geomembran.

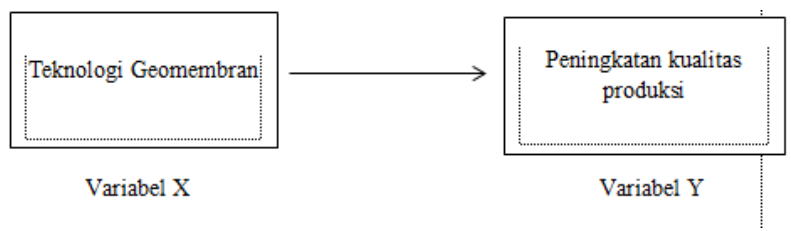

\section{DAFTAR PUSTAKA}

Sulistyaningsih,Sugiono,\&Sedyawati(2010).

Pemurnian Garam Dapur Melalui Metode Kristalisasi Air Tua Bahan

Pengikat Pengotor $\mathrm{Na}_{2} \mathrm{C} 2 \mathrm{O} 4-\mathrm{NaHCO}_{3}$ dan $\mathrm{Na} 2 \mathrm{C} 2 \mathrm{O} 4$ - Na2CO3. Jurnal Kimia, $\mathrm{I}(8), 26-3$.

Oktavian,R.(2013).Teknologi Produksi Garam Pada Lahan Tanah Di PT.Garam (Persero)

Kabupaten Sampang, Laporan PKL, Jurusan Ilmu Kelautan. Universitas Trunojoyo Madura. Bangkalan.

Putra,Giardo Permadi, Zainul Arifin, \& Sunarti. 2017. Pengaruh Kualitas Produk Terhadap Keputusan Pembelian dan Dampaknya Terhadap Kepuasan Konsumen. Jurnal Administrasi Bisnis (JAB). Vol.48 No.1. hal 125.

Anggraeni, Dita putri, Srikandi Kumadji, \& Sunarti. 2016. Pengaruh Kualtias Produk Terhadap Kepuasan \& Loyalitas Pelanggan. Jurnal Administrasi Bisnis (JAB). Vol.37 No.1. hal 173.

Gustiawati,Nurul, \&Aprilianti. 2016. Peningkatan Kualitas Garam Rakyat dengan Metode Rekristalisasi. Skripsi. Jurusan Teknik Kimia. Fakultas Teknologi Industri, Institut tekonologi sepuluh nopember. SURABAYA. Hal 5-9.

Abdullah,Zainal Arif, \&Aprilina Susandini. 2018. Media Produksi (Geomembrane) Dapat Meningkatkan Kualitas \& Harga Jual Garam. Eco- Entrepreneurship. Vol.3 No.2. hal 26-27. 